\title{
Oral Health Assessment, an Epidemiological Survey among Dental Patients from Lahore, Pakistan
}

\author{
Fatima Ghani ${ }^{1}$, Zarfishan TahiR $^{2}$, Nadia Mukhtar ${ }^{2 *}$, Tahir Yaqub ${ }^{3}$, Tasra Bibi $^{4}$ \\ ${ }^{1}$ CMH Lahore Medical And Dental College, Lahore; ${ }^{2}$ Primary and Secondary Health care Department, Lahore; \\ ${ }^{3}$ Department of Microbiology, University of Veterinary and Animal Sciences Lahore; ${ }^{4}$ Department of Pathology, \\ University of Veterinary and Animal Sciences Lahore, Pakistan.
}

\begin{abstract}
Objective:Present study was conducted to assess the oral health practices, oral hygiene habits and associated dental problems among subjects from Lahore, Pakistan. Methods: This cross sectional epidemiological study was consisted of sixty two, 11-56 years old dental subjects from both genders enrolled from Jinnah hospital, Lahore for oral examination. Questionnaire included the questions regarding basic demographic information, medical history, life style and behavior and dietary history was distributed among enrolled subjects and they were interviewed using the World Health Organization health protocols. Results: From the dental enrolled subjects, $30.6 \%$ patients have chronic diseases which included kidney dysfunction, digestive problems, respiratory diseases, Diabetes, bone and joint problems and hypertension. The prevalence of cavities was high $82.3 \%$ among dental patients and remaining have swollen gums, abscess and pain and of them $75.8 \%$ were underwent through past treatment of dental filling, implant, extraction and root canal. Teeth sensitivity and chewing difficulty was experienced by $88.7 \%$ of subjects. For dental hygiene, tooth brushing was carried out by $85.5 \%$, miswak by $9.7 \%$ and low percentage of rinsing practice that was $4.8 \% .91 .9 \%$ of the subjects have visited the dentist when needed and the remaining percentage have practice of dentist visit one month or two months. About dietary history of usage of artificial sweetener, candies, ice-cream, rusk, carbonated beverages, chewing gums, cookies, snakes, eggs, meat, milk, cheese, yogurt, fruits, vegetables etc. was varied among subjects with respect to daily, weekly and never use. Conclusion: Awareness programs should be conducted to promote oral health awareness and its impact on systemic health amongst the general population of Lahore. Continuous implementation of oral health awareness programs in community can improve the oral health and better oral health practices results in better quality of life.
\end{abstract}

Keywords: Oral health, Dietary history, Chronic diseases, Dental hygiene, Awareness programs

Editor | Muhammad Nauman Zahid, Quality Operations Laboratory, University of Veterinary and Animal Sciences, Lahore, Pakistan.

Received | July 08, 2018 Accepted | August 12, 2018; Published | September 26, 2018

*Correspondence | Nadia Mukhtar, Primary and Secondary Health care Department, Lahore, Pakistan; Email: nadiamukhtar84@yahoo.com

Citation | Ghani F, Tahir Z, Mukhtar N, Yaqub T, Bibi T (2018). Oral health assessment, an epidemiological survey among dental patients from lahore, pakistan. S. Asian J. Life Sci. 6(2): 54-57.

DOI | http://dx.doi.org/10.17582/journal.sajls/2018/6.2.54.57

ISSN | 2311-0589

Copyright $(\subset) 2018$ Ghani et al. This is an open access article distributed under the Creative Commons Attribution License, which permits unrestricted use, distribution, and reproduction in any medium, provided the original work is properly cited.

\section{INTRODUCTION}

$\mathrm{M}$ any human beings believe that an attractive smile and good teeth are indicator of accurate oral fitness. In fact, oral fitness contributes to self-belief and preferred systemic fitness (Jain et al., 2013). In 1948, world health organization (WHO) came up with a new and more broadened meaning of the health. The exact definition states that health is, "a complete state of physical, mental and social well-being and not just the absence of infirmity". Then it states that dental health necessity be taken into consideration while certifying the term well-being (Butler, 1974). Humans gather dental practices as they develop into youth (Sanjay et al., 2014). Oral sicknesses may additionally cause signs and symptoms inclusive of ache, soreness, altered flavor, and a burning sensation. Additionally, oral signs and symptoms may intervene with the chewing of food, pronunciation of certain phrases and sounds, and smiling and socializing with confidence (Slade and Spencer, 1994). Generally, the oral mucosa is harbored by the microbial 
communities commonly termed as biofilms. These biofilms and the contaminated or poorly sterilized oral surgical tools are the major causes of systemic infections and other disorders that mainly include heart diseases, respiratory problems, diabetes mellitus, and severe gynecological complications (Roberts et al., 2010). Satisfactory oral health knowledge and personal practices containing diet guidance and caries attention are necessary for good oral health (Deinzer et al., 2010; Parker and Jamieson, 2010).

This is the first epidemiological survey in Lahore, Pakistan related to oral health assessment among different age groups. Main objectives of this study were: (1) To monitor the oral health status among literate and illiterate people. (2) To evaluate developments of oral diseases and conditions. (3) Assessment of efforts to prevent disabilities and diseases.

\section{MATERIALS AND METHODS}

\section{Study Design and Sample Size}

This cross sectional epidemiological study was carried out among the subjects and a questionnaire was distributed to them. Total 62 questionnaires were filled and each question was explained to all participants.Voluntary participation of the dental patients in the survey was made and interviews were conducted after the consent of patients. Questionnaire was based on the following data.

\section{DEMOGRAPHIC INFORMATION}

For basic demographic information, questions of patients name, age, gender, occupation, number of family members, blood group, area of residence, level of education were included.

\section{Medical History}

Medical history of the subjects was comprised of following questions: (1) What type of dental problem are you currently suffering from? (2) Have you undergone any tooth treatment during the past year? (3) If yes, specify? (4) Does any of your family members suffer from dental problems? (5) How many members of your family are suffering from dental problem? (6) Do you suffer from any chronic disease? (6) If yes, specify which one?

\section{LIFESTYLE AND BEHAVIOR}

For lifestyle they were asked for (1) What do you use for dental hygiene? (2) When do you brush your teeth? (3) How often do you visit your dentist? (4) Do you smoke?

\section{Dietary History}

Dietary history of the subjects included the questions (1) Do you find difficulty in having certain foods because of tooth/ gum problems? (2) If yes, what type of food item creates the problem? (3)Do you use any artificial sweetener? (4) Do you use flavored cereals? (5) How often do you drink carbonated beverages? (6) How often do you eat cheese? (7) How often do you eat candy? (8) How often do you eat ice cream or butter? (9) How often do you eat meat and eggs?

\section{Statistical Analysis}

The data were collected and compiled on MS Excel 2010 derived from questionnaires. This data was analyzed through one way analysis of variance (ANOVA) by using SPSS the Statistical Package of Social Science version 20.00 .

\section{RESULTS}

This epidemiological survey was consisted of $(n=62), 11$ 56 years old dental subjects from Jinnah hospital, Lahore for oral examination. Of these forty six $(74.19 \%)$ were females and sixteen $(25.81 \%)$ were male subjects. Their age ranges were $\leq 20 \mathrm{y}$ of $14(22.58 \%)$ subjects, $21-30 \mathrm{y}$ of 19 (30.65\%), 31-40y of 15 (24.19\%) and >40y of $14(22.58 \%)$ of subjects. Of the total subjects $53.23 \%$ were housewife, $29 \%$ were students and $17.74 \%$ were related to different occupations of teacher, baker, painter, clerk, shopkeeper, fisherman, cook, deriver, musician and employee at Wapda. Literacy rate was $82.3 \%$ and $17.7 \%$ were illiterate. The prevalence of cavities was high $82.3 \%$ among dental patients and remaining $17.7 \%$ have swollen gums, abscess, infection and pain and of them $75.8 \%$ were underwent through past treatment of dental filling, implant, extraction and root canal. Among the dental patients with cavities $46.8 \%$ have had family history of dental cavities and $53.2 \%$ had not. Percentage of subjects for teeth sensitivity and chewing difficulty was same $88.71 \%$. They have sensitivity to hot, cold, sweets, hard and chewy food. Among the dental enrolled subjects $30.6 \%$ patients have chronic diseases which included kidney dysfunction, digestive problems, respiratory diseases, Diabetes mellitus, bone and joint problems and hypertension and $69.4 \%$ have not. For dental hygiene, tooth brushing was carried out by $85.5 \%$, miswak (traditional tree-twig) by $9.7 \%$ and low percentage of rinsing of teeth that was $4.8 \%$. (Table 1). Frequency of oral hygiene was that $85.5 \%$ of the subjects did their teeth cleaning before breakfast, $11.3 \%$ before bed, $1.61 \%$ after breakfast and $1.61 \%$ five times. $93.55 \%$ of the subjects have visited the dentist when needed and the remaining percentage have practice of dentist visit one month (1.61\%), two months (1.61\%), 1 year (1.61\%) and never (1.61\%). Only $8 \%$ of subjects were smoking and remaining were not. About dietary history of usage of artificial sweetener, flavored cereals, candies, ice-cream, rusk/naan/bread, cakes, bakery products, fast foods, carbonated beverages, chewing gums, cookies, snakes, eggs, meat, milk, cheese, yogurt/ 
lassi, fresh, canned and dried fruits, nuts, jam, fruit juices, vegetables, chewing gums, sweetened drinks etc. was varied among subjects with respect to daily, weekly and never use (Table 2). A significant difference was found among all the variables $\mathrm{p}<0.05$.

Table 1: History of patients with tooth problem.

\begin{tabular}{lllll} 
Parameters & Yes & Yes (\%) & No & No(\%) \\
\hline Smoking & 5 & 8.06 & 57 & 91.94 \\
Chewing difficulty & 7 & 11.29 & 55 & 88.71 \\
\hline Use of artificial sweeteners & 2 & 3.23 & 60 & 96.77 \\
\hline Past Treatment & 46 & 74.19 & 16 & 25.81 \\
\hline Family History & 29 & 46.77 & 33 & 53.23 \\
Chronic Disease & 19 & 30.65 & 43 & 69.35 \\
Teeth Senstivity & 7 & 11.29 & 55 & 88.71
\end{tabular}

$\mathrm{P}=0.0042<.05$, Significant

Table 2: Effect of junk food on patient's dental health.

\begin{tabular}{|c|c|c|c|c|c|}
\hline Parameters & Daily & $\begin{array}{l}\text { Week- } \\
\text { ly<1 }\end{array}$ & $\begin{array}{l}\text { Weekly } \\
1\end{array}$ & $\begin{array}{l}\text { Week- } \\
\text { ly >1 }\end{array}$ & Never \\
\hline $\begin{array}{l}\text { Use of Bread/ } \\
\text { Rusk/Naan }\end{array}$ & 31 & 9 & 15 & 5 & 2 \\
\hline Use of Snacks & 5 & 29 & 9 & 10 & 9 \\
\hline Use of Cookies & 4 & 29 & 13 & 10 & 6 \\
\hline $\begin{array}{l}\text { Use of Flavored } \\
\text { cereals }\end{array}$ & 1 & 33 & 7 & 5 & 16 \\
\hline Use of Cakes & 1 & 28 & 12 & 10 & 11 \\
\hline $\begin{array}{l}\text { Use of Bakery } \\
\text { products }\end{array}$ & 1 & 24 & 6 & 8 & 23 \\
\hline Use of Fast food & 12 & 32 & 11 & 5 & 2 \\
\hline $\begin{array}{l}\text { Use of Fresh } \\
\text { fruits }\end{array}$ & 14 & 6 & 13 & 26 & 3 \\
\hline $\begin{array}{l}\text { Use of Canned } \\
\text { fruits }\end{array}$ & 33 & 13 & 7 & 6 & 3 \\
\hline $\begin{array}{l}\text { Use of Dried } \\
\text { fruits }\end{array}$ & 5 & 30 & 8 & 6 & 13 \\
\hline Use of Nuts & 8 & 32 & 6 & 5 & 11 \\
\hline Use of Jam & 1 & 22 & 6 & 3 & 30 \\
\hline $\begin{array}{l}\text { Use of Fruit } \\
\text { juice }\end{array}$ & 5 & 30 & 4 & 9 & 14 \\
\hline $\begin{array}{l}\text { Use of Raw } \\
\text { vegetables }\end{array}$ & 6 & 20 & 12 & 17 & 7 \\
\hline Use of Milk & 23 & 14 & 7 & 10 & 8 \\
\hline $\begin{array}{l}\text { Use of Yougurt/ } \\
\text { Lassi }\end{array}$ & 11 & 15 & 8 & 16 & 12 \\
\hline Use of Cheese & 1 & 6 & 4 & 8 & 43 \\
\hline Use of Meat & 8 & 11 & 9 & 29 & 5 \\
\hline Use of Eggs & 9 & 13 & 12 & 24 & 4 \\
\hline $\begin{array}{l}\text { Use of Car- } \\
\text { bonated baver- } \\
\text { ages }\end{array}$ & 3 & 24 & 8 & 15 & 12 \\
\hline
\end{tabular}

July-December 2018| Volume 6 | Issue 2 | Page 56

\begin{tabular}{llllll}
$\begin{array}{l}\text { Use of Sweet- } \\
\text { ened drinks }\end{array}$ & 2 & 19 & 12 & 13 & 16 \\
$\begin{array}{l}\text { Use of Ice cream } \\
\text { Use of Candies }\end{array}$ & 3 & 34 & 7 & 5 & 13 \\
$\begin{array}{l}\text { Use of Chewing } \\
\text { gums }\end{array}$ & 3 & 11 & 1 & 4 & 43 \\
$\begin{array}{l}\text { Average } \\
\mathrm{P}=0.0000<.05 \text {, Significant }\end{array}$ & 20.83 & 8.38 & 10.67 & 14.08 \\
\hline
\end{tabular}

\section{DISCUSSION}

The survey has provided a wide-ranging indication of dental hygiene practices, awareness and lifestyle of people related to their oral health. About eighty percent $(80 \%)$ of Jordanian people went through dental checkup and treatment on an uneven basis and visited the dentist only for emergencies (Taani, 2002). This percentage is near about to our percentage that $93.55 \%$ subjects only visited dentists when they needed. This demonstrated that people do not have awareness of their regular dental examination. It was observed in past study that majority of the enrolled subjects used tooth brush and tooth paste to clean their teeth (Goel et al., 2015; Kumar et al., 2017; Zaborskyte, 2003). This investigation is correlated to our study that $95.2 \%$ of the subjects did teeth cleaning with brush and miswak. This could probably reflect the awareness or affordability for tooth brush and paste among the study population or this indicated that participants do have basic knowledge about teeth cleaning. In a previous study carried out in Chennai reported that children used charcoal as a medium to brush their teeth than the tooth brush (Mahesh, 2005). Tooth brush usage is key measure of oral health hygiene (Hitz, 2011). However, in another study miswak using subjects were higher (59\%) as compared to our study (Okemwa et al., 2010).

Major percentage (92.4\%) of students was reported for their teeth cleaning and among them $48.7 \%$ of students cleaning teeth once daily. $55.8 \%$ of them having a dental check-up in the last 6 months. Concerning smoking, 63.4\% stated to have never smoked though $17.3 \%$ described that frequent smoking (Shah, 2017; Sreenivasan, 2016). These findings are correlated to present study. Oral health practices including diet, actual oral hygiene and smoking are pivotal to the occurrence of oral diseases.

Enrolled subjects of the present study have dental associated problems and past studies have proven that poor oral hygiene persons had increased risk of developing several oral health complications (Axelsson et al., 2004).

Results of present study declared the fact that participants are unaware of the ways of practicing good oral hygiene. 
These findings presents a challenge to improvement of oral health in the 21st century. Dental service utilization, patients' compliance, and aprofessional style oriented strategies toward prevention might be useful to improve the oral health (Rimondini et al., 2001; Yin et al., 2017). Kressin et al. (2003) studied that multiple hygiene behaviors were associated with greater tooth retention. So, dental health education can only be tailored if there is a baseline data about people's current oral hygiene behavior.

\section{ACKNOWLEDGEMENTS}

The authors are thankful to all the study participants for their trust and collaboration.

\section{CONFLICT OF INTEREST}

The authors declared that they have no conflict of interests.

\section{AUTHORS CONTRIBUTION}

All the authors contributed equally

\section{REFERENCES}

-Axelsson P, Nystrom B, Lindhe J (2004). The long-term effect of a plaque control program on tooth mortality, caries and periodontal disease in adults. Results after 30 years of maintenance. J. Clin. Periodontol. 31:749-57. https://doi. org/10.1111/j.1600-051X.2004.00563.x

- Butler RN (1974). Successful aging and the role of the life review. J. Am. Geriatr. Soc.22(12): 529-35. https://doi. org/10.1111/j.1532-5415.1974.tb04823.x

- Deinzer R, Micheelis W, Granrath N, Hoffmann T (2009). More to learn about: periodontitis-related knowledge and its relationship with periodontal health behaviour. J. Clin. Periodontol. 36(9):756-64. https://doi.org/10.1111/j.1600051X.2009.01452.x

- Goel R, Vedi A, Veeresha KL, Sogi GM, Gambhir RS (2015). Oral hygiene practices and dental caries prevalence among $12 \& 15$ years school children in Ambala, Haryana-A crosssectional study. J. Clin. Exper. Dent. 7(3):374. https://doi. org/10.4317/jced.52303

- Hitz LI, Lambrecht JT (2011). Oral Care. Curr. Probl. Dermatol. 40:107-15. https://doi.org/10.1097/ MLR.0b013e318223a9f1

- Jain A, Gupta J, Aggarwal V, Goyal C (2013). To evaluate the comparative status of oral health practices, oralhygiene and periodontal status amongst visually impaired and sighted students. Spec. Care. Dent. 33:78-84.

- Kressin NR, Boehmer U, Nunn ME, Spiro III A (2003). Increased preventive practices lead to greater tooth retention. J. Dent. Res. 82(3):223-7. https://doi. org/10.1177/154405910308200314

- Kumar AMS, Irshana R, Hegde S, Rajesh KS (2017). Assessment of oral hygiene habits and oral health awareness among pre-university students (16-18yrs) of Mangalore"- A Questionnaire Study. J. Dent. Med. Sci. 16(3): 113-7.

- Mahesh KP, Joseph T, Varma RB, Jayanthi M (2005). Oral health status of 5 years and 12 years school going children in Chennai city - An epidemiological study. J. Indian. Soc. Pedod. Prev. Dent. 23:17-22. https://doi.org/10.4103/09704388.16021

- Okemwa KA, Gatongi PM, Rotich JK (2010). The oral health knowledge and oral hygiene practices among primary school children age 5-17 years in a rural area of Uasin Gishu district, Kenya. East. Afr. J. Public Health. 7:187-90.

- Parker EJ, Jamieson LM (2010). Associations between indigenous Australian oral health literacy and self-reported oral health outcomes. BMC Oral Health. 10:3. https://doi. org/10.1186/1472-6831-10-3

- Rimondini L, Zolfanelli B, Bernardi F, Bez C (2001). Self-preventive oral behavior in an Italian university student population. J. Clin. Periodontol. 28:207-11. https://doi. org/10.1034/j.1600-051x.2001.028003207.x

- Roberts AP, Mullany P (2010). "Oral biofilms: a reservoir of transferable, bacterial, antimicrobial resistance." Expert review of anti-infective therapy. 8(12): 1441-50. https://doi. org/10.1586/eri.10.106

- Sanjay V, Shetty S, Shetty R, Managoli N, Gugawad S, Hitesh D (2014). Dental health status among sensoryimpaired and blind institutionalized children aged 6 to 20 years. J. Int. Oral. Health. 6:55.

- Shah AH, ElHaddad SA (2015). Oral hygiene behavior, smoking, and perceived oral health problems among university students. J. Int. Soc. Prev. Community Dent. 5:327-33. https://doi.org/10.4103/2231-0762.161765

- Singh MS, Tuli AK (2013). A comparative evaluation of oral hygiene practices, oral health status, and behavior between graduate and post-graduate dentists of North India: An epidemiological survey. J. Int. Soc. Prev. Community Dent. 3(1): 19-24. https://doi.org/10.4103/2231-0762.115713.

- Slade GD, Spencer AJ (1994). Development and evaluation of the oral health impact profile. Community Dent. Health. 11(1): 3-11.

- Sreenivasan PK, Prasad KV, Javali SB (2016). Oral health practices and prevalence of dental plaque and gingivitis among Indian adults. Clin. Exper. Dent. Res. 2(1):6-17. https://doi.org/10.1002/cre2.15

- Taani DQ (2002). Periodontal awareness and knowledge and pattern of dental attendance among adults in Jordan. Int. Dent. J. 52:94-8. https://doi.org/10.1111/j.1875595X.2002.tb00607.x

- Yin W, Yang YM, Chen H, Li X, Wang Z, Cheng L, Yin QD, Fang HZ, Fei W, Mi FL, Nie MH (2017). Oral health status in Sichuan Province: findings from the oral health survey of Sichuan, 2015-2016. Int. J. Oral Sci. 9(1):10. https://doi. org/10.1038/ijos.2017.6

- Zaborskyte A, Bendoraitiene E (2003). Oral hygiene habits and complaints of gum bleeding among schoolchildren in Lithuania. Stomatologija. 5:31-6. 